\title{
La llegada al poder y el ejercicio del mismo desde la intuitiva perspectiva de Nicolás Maquiavelo
}

\author{
" The arrival to the power and the exercise of the same \\ from the intuitive perspective of Nicolas Maquiavelo
}

\author{
Elvis Andrés Ruiz Viera \\ Universidad Libre, Colombia
}

\section{Resumen}

Esta actividad se adelanta con normas APA 6 y tiene como método central el análisis e interpretación del libro El príncipe con el fin de precisar las inquietudes y opiniones alrededor del tema central, a partir de las formas de poder y modelos de Estado. Este nace de inquietudes teóricas y conceptuales alrededor de la contextualización del poder en las distintas etapas de su evolución y revisando aquellos símiles históricos con la realidad política y de Estado de hoy, sobre todo por la incidencia histórica que tiene la Edad Moderna para el estudio, la composición misma del Estado, y los sistemas que lo anteponen y los que surgieron luego de su terminación.

Palabras clave: Nicolás Maquiavelo, estado, política y derecho administrativo.

\begin{abstract}
This activity is carried out with APA 6 standards and its central method is the analysis and interpretation of the book The Prince in order to specify the concerns and opinions around the central theme, based on the forms of power and State models. This is born of theoretical and conceptual concerns about the contextualization of power in the different stages of the evolution of the State and reviewing those historical similes with the political reality and State of today, especially by the historical incidence that the modern age has for the I study the composition of the State itself, and the systems that precede it and those that emerged after its termination.
\end{abstract}

Keywords: Nicolás Maquiavelo, state, politics and administrative law.

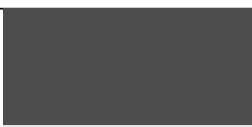

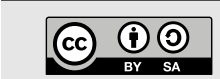

() 2019

Correspondencia de autor:

elviswruiz@hotmail.com elvisa-ruizv@unilibre.edu.co

s. 


\section{Introducción}

A lo largo de la historia se ha tratado de determinar la evolución del Estado y las formas en las que este debe ser "ideal", es decir, un sinnúmero de personajes se han dedicado a describir su utopía de Estado, sin duda, algunos han acertado y otros no tanto. Este análisis, a juicio propio, debe analizarse desde una perspectiva de la realidad, más allá de las ideas o ideologías que se tengan frente a la conformación de un Estado y la búsqueda de un modelo idealizado.

Este texto se basa en uno de los tratados más importantes y con mayor renombre mundial en referencia al tema a tratar: el Estado, su conformación y configuración; pero no desde una óptica solamente actual sino desde una perspectiva de la realidad atemporal. Este tratado se titula, secularmente en el idioma castellano como El Príncipe pero que en relación a su título original en italiano -Il principe- o en latín -De principatibus- debería titularse De Los Principados, y que además, luego de una revisión cuidadosa, guarda inmersa lógica que este último sea su título toda vez que el objeto central del texto es un modelo de Estado monárquico alrededor de la figura de los príncipes.

Tanto es así que su autor, Nicolás Maquiavelo (2004), hace una remembranza de ejemplos que se caracterizan por redondear o explicar aquello que quería describir. Cabe resaltar que el leguaje es eminentemente medieval gracias a la época en la que este se escribió, en el año 1513 y que fue oficialmente publicado por primera vez en 1532. Por ello, a este tratado se le han realizado varias traducciones a nuestra legua y un sinnúmero de editoriales lo han distribuido en el mundo.

En contexto, se torna objetivo hacer una revisión exhaustiva de la relación de poder, desde un punto de vista de desear obtenerlo a través de la captura de un territorio $y_{\text {, }}$ por ende, sus medios de producción; es decir, la forma en que se ejerce este poder al interior del Estado.

Pero, en este sentido poder no solo es adquirirlo, sino tener la virtud de mantenerlo a través de los distintos roles que se juegan al interior del Estado -más aún en la época a la que nos remontamos- gracias a que no existía lo que hoy conocemos como controles del poder estatal. 
Se dice con este análisis, que Maquiavelo se debe entender como un hombre perverso y calculador (por aquello del peyorativo "maquiavélico") bajo el entendido de que intuyó el modelo de Estado Moderno. Es decir, que Maquiavelo es un republicanísta observando una realidad, pero no desde el estudio de la persona humana, sino desde la observancia del Estado y el comportamiento de las personas en frente a cada modelo. En contexto, Maquiavelo no estructuró o creó el Estado Moderno, sino que lo visualizó desde el análisis que hizo con el seguimiento del Estado como tal.

Con todo, se requiere plantear como hipótesis la relación entre los virtuosos y los no virtuosos al momento de adquirir el poder, según el autor, lo que se resuelve haciendo una mirada no solo ejemplificadora de los sucesos sino, del grueso de las consideraciones del tratadista que, grosso modo, son de gran impacto para la teoría jurídica de nuestros tiempos.

\section{Contenido}

\section{Contextualización general: los virtuosos y los no virtuosos al momento de adquirir el poder}

El autor en su relato pretende determinar, a través de ejemplos, aquellos actos 0 momentos que determinan lo positivo de cómo adquirir el poder y, lo más complejo, mantenerse en él. Maquiavelo expresa que:

Los hombres caminan casi siempre por caminos trillados ya por otros, y no hacen casi más que imitar a sus predecesores, en las acciones que se les ve hacer; pero como no pueden seguir en todo el camino abierto por los antiguos, ni se elevan a la perfección de los modelos que ellos se proponen, el hombre prudente debe elegir únicamente los caminos trillados por algunos varones insignes, e imitar a los de ellos que sobrepujaron a los demás, a fin de que si no consigue igualarlos, tengan sus acciones a lo menos alguna semejanza con las suyas. (p.12)

En otras palabras, a juicio propio, lo que hace Maquiavelo es generar una alerta de doble impacto a quienes llama hombres, dirigiéndose a quien pretende llegar al poder: primero dejando claro que en materia de Estado siempre existe un antecesor 
aun cuando sean nuevos $y$, segundo, indicando aquellos aspectos imitables 0 semejantes al momento de estar en el poder.

Es por ello, que para el literato se deben imitar "los hombres que, con su propio valor y no con la fortuna, llegaron a ser príncipes, digo que los más dignos de imitarse son: Moisés, Ciro, Rómulo, Teseo y otros semejantes" (p.12). Afirmación que, si se interpreta sistémicamente, se debe revisar la forma económica por la que los hombres pueden llegar al poder y pone como ejemplos a los antes citados.

Entonces resulta que Maquiavelo se afana por fijar posiciones frente a lo anterior, pero basado en la nueva configuración de los Estados, acotando posiciones como:

Que en los principados que son nuevos en un todo, y cuyo príncipe, por consiguiente, es nuevo, hay más o menos dificultad en conservarlos, según que el que los adquirió es más o menos valeroso. Como el suceso por el que un hombre se hace príncipe, de particular que él era, supone algún valor o dicha, parece que la una o la otra de estas dos cosas allanan en parte muchas dificultades; sin embargo, se vio que el que no había sido auxiliado de la fortuna, se mantuvo por más tiempo. Lo que proporciona también algunas facilidades, es que no teniendo un semejante príncipe otros Estados, va a residir en aquel de que se ha hecho soberano. (p.12)

Esto es, el autor se refiere a que depende del príncipe y que gracias a su forma de gobernar, es decir, a mantener el poder en sus dimensiones expuestas. Esto, basado en el valor que origina por qué una persona se hace príncipe, en que la virtud es poder llegar por medios financieros propios y que esto legitima, en su mayoría, su asentamiento en el poder por mayor tiempo.

Todo lo contrario se plantea en cuanto a que el príncipe, al presentarse en el naciente Estado, lo hace con recursos económicos y medios de poder ajenos. Frente a lo cual agrega Maquiavelo (2004):

Los que de particulares que ellos eran, fueron elevados al principado por la sola fortuna, llegan a él sin mucho trabajo; pero tienen uno sumo para la conservación suya. No hallan dificultades en el camino para llegar a él, porque son elevados como en alas; pero cuando le 
han conseguido se les presentan entonces todas las especies de obstáculos. (p.14)

En contexto, vale resaltar que para el autor no es suficiente hacerse al poder, sino llegar a él con fundamento de legitimidad de mantenerlo, pero que dicha raíz se hace débil en los casos en los que se depende de la compasiva actitud de quienes, a través de su dinero y/o las armas, generaron virtud para lograr el ascenso 0 llegada al mismo. Por ello Maquiavelo (2004) le da un alcance al afirmar que: "estos príncipes no pudieron adquirir su Estado más que de uno u otro de estos dos modos: o comprándolo o haciéndolo dar por favor" (p.14).

Se podría, entonces, afirmar que el literato italiano resalta a aquellos que obtienen el poder de los nuevos principados a través de un trabajo, lo cual les genera una estabilidad -generalmente política- la cual se supedita a los cambios que se generan a través de las normas nacientes y la forma en la que estas impactan en la cotidianidad del Estado mismo a través de lo que, en nuestros tiempos podríamos llamar una "política de seguridad" (Maquiavelo, 2004, p.13).

Ampliando lo expuesto sobre los modelos a seguir, Maquiavelo acentúa una posición clara de cómo no debe actuarse frente a la captura de nuevos Estados, expresando que quien:

Obra siguiendo malos consejos, está precisado siempre a tener la cuchilla en la mano; y no puede contar nunca con sus gobernados, porque ellos mismos, con el motivo de que está obligado a continuar y renovar incesantemente semejantes actos de crueldad, no pueden estar seguros. (p.20)

En otras palabras, sintetiza que de nada sirve al nuevo jefe arremeter con nuevas praxis al interior del Estado, afectando a los conciudadanos con leyes y costumbres completamente drásticas y distantes a las que están habituados. Partiendo de que, al interior de la ciudadanía, existen sujetos activos quienes han obtenido beneficio de leyes preliminares.

Desde una óptica sistemática y no exegética, se podría agregar, a juicio propio, que Maquiavelo (2004) conjuga la virtud del jefe en relación a la manera en que este se entienda con la ciudadanía y "examinando sus acciones y conducta", además de lo 
que antes se ha expuesto de la manera en que este encuentre un medio expedito de introducir en el Estado aquello que genera su mejor conveniencia (p.21). Afirmación que es equívoca en su conclusión gracias a que la función de este es procurar intereses eminentemente generales y no solo los personales, que, incluso, son chocantes para los mencionados habitantes. Agrega el autor sobre lo antes descrito:

Los actos de severidad mal usados son aquellos que, no siendo más que en corto número a los principios, van siempre aumentándose, y se multiplican de día en día, en vez de disminuirse y de mirar a su fin, refiriéndose a los que llegaron al principado por vía de maldades. (p.20)

Lo anterior, es todo lo que, se cree, no es correcto adelantar por razones de simple lectura crítica. En contraposición, se entiende el modelo de principado civil, en términos de Maquiavelo, que se forja con la llegada al poder y la consecución de actuaciones de potestad que se generen. Por ello, el autor contrapone algunas formas de acceder y mantenerse en el poder y que relata, en síntesis, así:

El que consigue la soberanía con el auxilio de los grandes se mantiene con más dificultad que el que la consigue con el del pueblo; porque siendo príncipe, se halla cercano de muchas gentes que se tienen por iguales con él, y no puede mandarlas ni manejarlas a su discreción. (p.21)

Entonces, afirma Maquiavelo (2004) que "el que llega a la soberanía con el favor popular se halla solo en su exaltación" (p.20), asumiendo este como punto eje central de certeza, gracias a su fundamentación y raíces.

\section{Conclusiones}

Maquiavelo advierte que "un príncipe debe, ante todas cosas, conducirse con sus gobernados de modo que ninguna casualidad, buena o mala, le haga variar" (p.21); generando firmeza y tesón.

Es decir, para el tratadista italiano, en consideración propia, lo que pretende en relación al tema planteado no es describir un modelo expedito de como hacerse al poder y de cómo mantenerse en él sino, determinar las formas en que se podría 
obtener una llegada acertada y la legitimación de ella, bajo un gobierno o control basado en los intereses que el mismo pueblo, y por en ende su gobernante, exprese.

En otras palabras, Maquiavelo no pretende ejemplificar o codificar un modelo de Estado, sino impulsar a los gobernantes a actuar correctamente basado en la situación, pero con una mirada en la forma en cómo que se obtuvo el poder y la devoción a quienes contribuyeron a que este resultara efectivo.

Con todo, se puede afirmar que la fusión idónea de cómo podría resultar mejor la forma de gobernar, es la de llegar al poder por resultados y esfuerzos propios en compañía del pueblo, y no con la virtud de otros como la nobleza, con contribuciones como sus riquezas y su fuerza. Definitivamente, la conclusión más relevante es determinar que en cualquier sistema, por remoto que sea, la clave es gobernar con y por los ciudadanos, quienes son, en definitiva, la fuente generadora de la eficacia del Estado.

\section{Referencia bibliográfica}

Maquiavelo, N. (2004). El príncipe. Madrid, España: Espasa-Calpe S.A. 
